Proc. Indian Acad. Sci. (Chem. Sci.), Vol. 105, No. 6, December 1993, pp. 513-525.

(C) Printed in India.

\title{
Photosensitizing properties of squaraine dyes
}

\author{
SURESH DAS ${ }^{1}$, K GEORGE THOMAS $^{1}$, PRASHANT V KAMAT $^{2}$ \\ and $M$ V GEORGE ${ }^{1,2 *}$ \\ ${ }^{1}$ Photochemistry Research Unit, Regional Research Laboratory (CSIR), Trivandrum \\ 695019, India \\ ${ }^{2}$ Radiation Laboratory, University of Notre Dame, Notre Dame, IN 46556, USA
}

\begin{abstract}
The present report summarises our results on the photophysical and photochemical investigations of a series of squaraine dyes which exhibit intense and sharp absorption bands in the visible and near infrared regions. The intramolecular charge-transfer transitions arising from the "donor-acceptor-donor" arrangements of these dyes have an interesting effect on their excited state properties. The major nonradiative decay process of squaraines is by rotation about the $\mathrm{C}-\mathrm{C}$ bonds between the central cyclobutane unit and its neighbouring phenyl groups. Microencaging of one of the dyes by $\beta$-cyclodextrin or poly(4-vinylpyridine) was found to restrict this motion, bringing about up to 90-fold enhancement in its fluorescence yield. These aspects as well as the dynamics of charge transfer from the excited singlet state of some of the squaraine dyes to $\mathrm{TiO}_{2}$ and the recombination of the injected charge with the dye radical cation are discussed.
\end{abstract}

Keywords. Photochemistry of squaraine dyes; $\beta$-cyclodextrin complexes; poly(4-vinylpyridine) complexes; $\mathrm{TiO}_{2}$-photosensitization.

\section{Introduction}

Squaric acid is known to undergo condensation reactions with a variety of nucleophiles to form 1,3-disubstituted derivatives (squaraines), which have very strong absorption in the visible and near infrared regions (Sprenger and Ziegenbein 1966; Schmidt 1980). The chemistry of squaric acid and other oxocarbons (Seitz and Imming 1992) and near-infrared dyes (Fabian et al 1992) have been reviewed recently. Although the technological applications of squaraine dyes in organic solar cells (Morel et al 1984; Piechowski et al 1984), xerographic photoreceptors (Tam 1980; Law 1993) and optical recording media (Emmelius et al 1989) have been extensively investigated, reports on the photophysical properties of squaraine dyes have been limited (Loutfy et al 1983; Law 1987, 1989, 1990; Vieira et al 1991). MNDO and CNDO calculations on the ground and excited states of bis[(4-dimethylamino)phenyl] squaraine (1)<smiles>CN(C)c1ccc(C2C([O-])C(c3ccc(N(C)C)cc3)C2[O-])cc1</smiles>

* For correspondence 
have shown that the molecule is highly polarized with the amino moiety being an electron donor (D) and the central cyclobutane unit being an electron acceptor (A) (Bigelow and Freund 1986).

These calculations also indicate that the $S_{0} \rightarrow S_{1}$ electronic excitation is accompanied by a charge transfer (CT), which is primarily confined to the central $\mathrm{C}_{4} \mathrm{O}_{2}$ unit, with a small degree of CT from the aniline moiety. However, the calculations indicate that both the $S_{0}$ and $S_{1}$ states are highly polarized intramolecular D-A-D CT states. The charge-transfer nature of these dyes also brings about interesting effects in their solid state chemistry. Extensive intermolecular charge transfer interactions in the solid state cause a red-shift accompanied by a broadening of their absorption bands. These intermolecular interactions also make these dyes highly photoconductive in the solid state. Highly conducting polymeric forms of such oxocarbon dyes have also been recently reported by Havinga and Wynberg (Emsley 1992).<smiles>CN(C)c1ccc(C2=C([O-])C(c3ccc(N(C)C)cc3)C2=O)cc1</smiles>

SQ 1<smiles>CC(=O)OC1=C(c2[nH]c(C)c(C)c2C)C(=O)C1=C1NC(C)=C(C(C)=O)C1=O</smiles>

SQ 3<smiles>CN(C)c1ccc(C2=C([O-])C(=C3C=CC(=O)C3=O)C(=O)C2O)c(O)c1</smiles>

SQ 2<smiles>O=C1C=CC(=C2C(=O)C(c3ccc(O)cc3O)=C2O)C(O)=C1</smiles>

SO 4<smiles>O=C1C=C(O)C(=C2C(=O)C(c3c(O)cc(O)cc3O)=C(O)C2O)C(O)=C1</smiles>

Chart 1.

SQ 5

Multiple emission bands have been observed for SQ1 (chart 1) and its derivatives in solution. In a detailed study involving the effects of solvent and temperature on the emission spectra of these dyes, three emission bands have been observed which have been assigned to emission from the free dye $(\alpha)$, dye-solvent complex $(\beta)$ and a twisted excited state resulting from the $\mathrm{C}-\mathrm{C}$ bond rotation $(\gamma)$ (Law and Bailey 1987).

Here, our work on the spectral characterization of the excited singlet, triplet and redox states of the squaraine dyes SQ1-SQ5 (chart 1), the hydrophobic interactions of SQ5 with $\beta$-cyclodextrin and poly(4-vinylpyridine), as well as the dye sensitization of a large band gap semiconductor, $\mathrm{TiO}_{2}$, are discussed.

\section{Experimental}

The squaraine dyes SQ1-SQ5 were synthesised by reacting squaric acid with the appropriate nucleophiles, by reported procedures (Sprenger and Ziegenbein 1966, 1968; Schmidt 1980). All solvents were of spectroscopic grade. Colloidal suspensions of $\mathrm{TiO}_{2}$ were prepared by a method described earlier (Kamat 1989). The details of 
quantum yield measurements, as well as the experimental set-up used for flashphotolysis and pulse-radiolysis have been described earlier (Das et al 1992a; Kamat et al 1992).

\section{Results and discussion}

\subsection{Excited singlet, triplet and redox states}

3.1a Bis[4-(dimethylamino)phenyl]squaraine derivatives: The spectroscopic characteristics of the squaraine dyes SQ1-SQ3, as well as their excited and redox states are summarised in table 1 (Kamat et al 1992; Patrick et al 1992).

Both SQ1 and SQ2 have sharp absorption bands with absorption maxima at 628 and $636 \mathrm{~nm}$, respectively. The fluorescence quantum yield and fluorescence lifetime of SQ2 are about twice that of SQ1. It has been suggested that the substituent $\mathrm{OH}$ groups in SQ2 facilitate hydrogen bonding between these groups and the CO-group in the cyclobutane ring, which can restrict the rotational relaxation process of the excited state (Law 1987). The excited singlets of SQ1 and SQ2 in methylene chloride were generated by direct excitation with $532 \mathrm{~nm}$ pulse. The transient absorption spectra recorded at different time intervals, following laser pulse (18 ps) excitation of SQ1 is shown in figure 1. As discussed in an earlier section, the excited singlet state

Table 1. Excited state properties of squaraine dyes.

\begin{tabular}{|c|c|c|c|c|c|c|c|c|c|c|}
\hline Dye & $\begin{array}{l}\text { Absorp- } \\
\text { tion } \\
\max \\
(\mathrm{nm})\end{array}$ & $\begin{array}{l}\text { Emis- } \\
\text { sion } \\
\max \\
(\mathrm{nm})\end{array}$ & $\phi_{f}$ & $\begin{array}{c}\text { Absorp- } \\
\text { tion } \\
\max \\
(\mathrm{nm})\end{array}$ & $\begin{array}{c}\tau_{s} \\
(\mathrm{~ns})\end{array}$ & $\phi_{T}$ & $\begin{array}{c}\text { Absorp- } \\
\text { tion } \\
\max \\
(\mathrm{nm})\end{array}$ & $\begin{array}{c}E^{0} D / D^{+} \\
V \text { vs SCE }\end{array}$ & $\begin{array}{c}\text { Radical } \\
\text { anion } \\
\lambda \max (\mathrm{nm})\end{array}$ & $\begin{array}{c}\text { Radical } \\
\text { cation } \\
\lambda \max (\mathrm{nm})\end{array}$ \\
\hline SQ1 & 628 & 654 & 0.45 & 480 & 1.5 & $<10^{-3}$ & 540 & $0 \cdot 305$ & 400 & 550 \\
\hline SQ2 & 636 & 658 & 0.84 & 475 & 3.0 & $<10^{-3}$ & 565 & 0.365 & - & 545 \\
\hline SQ3 & 568 & 587 & 0.08 & 442 & 0.22 & 0.007 & 420 & 0.976 & 435 & 505 \\
\hline
\end{tabular}

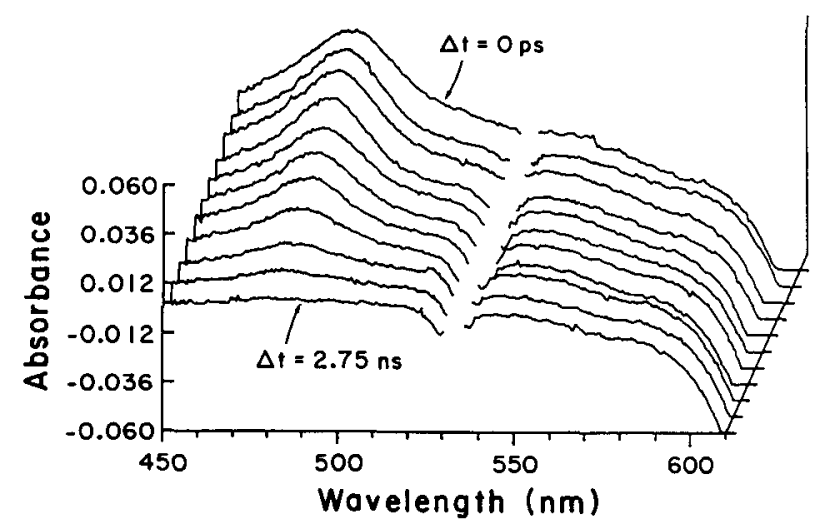

Figure 1. Transient absorption spectra of singlet-excited SQ1 in methylene chloride. The spectra were recorded, following $523 \mathrm{~nm}$ laser pulse excitation of $10 \mu \mathrm{M}$ SQ1 in methylene chloride, at time intervals of $0,0.05,0.1,0.15,0.2,0.25,0.35,0.5,0.75,1.75$ and $2.75 \mathrm{~ns}$. [Reprinted with permission from Kamat et al 1992 (C) 1992, Am. Chem. Soc.).] 
can also exist in the solute-solvent complex and twisted-excited state forms. An attempt was made to probe these states in transient absorption studies. Only a single absorption peak was observed in the wavelength region 400-600 nm. Our studies so far on the excited singlet states, viz. emission lifetimes and transient absorption measurements, have failed to gather supportive evidence for the existence of multiple singlet excited states.

To study the triplet excited states of the dyes by laser flash photolysis, a triplet-triplet energy transfer method using 9,10-dibromoanthracene (DBA) $\left(E_{T}=167.4 \mathrm{~kJ} \mathrm{~mol}^{-1}\right)$ as triplet sensitizer was employed, since direct excitation of the dyes led to very low yields of the dye triplets $\left(\phi_{T}=0.01\right)$. Time-resolved transient absorption spectra recorded after $355 \mathrm{~nm}$ pulse excitation of DBA in methylene chloride solution containing SQ1 is shown in figure 2. The transient absorption spectrum recorded immediately after laser pulse excitation $(\lambda \max : 425 \mathrm{~nm})$ corresponds to the sensitizer triplet. The absorption spectra recorded at time intervals greater than $10 \mu$ s correspond to the SQ1 triplet. The extinction coefficients were determined for the triplets of SQ1 and SQ2 by a method described earlier (Carmichael and Hug 1986). The triplet lifetimes of these dyes were $3.5 \times 10^{5} \mu \mathrm{s}$, indicating that the triplet excited states, unlike the singlet excited states, are insensitive to the presence of the $\mathrm{OH}$ group on the phenyl ring.

The dye radical cation spectra were recorded by generating these cations by pulse radiolysis of the dyes in methylene chloride solutions. Radiolysis of methylene chloride produces highly oxidising radicals such as $\mathrm{RCl}^{\circ}$ (Ford et al 1989). The oxidation potential of the squaraine dye is very low $(0.35$ and $0.41 \mathrm{~V}$ vs $\mathrm{Ag} / \mathrm{AgCl}$ for SQ1 and

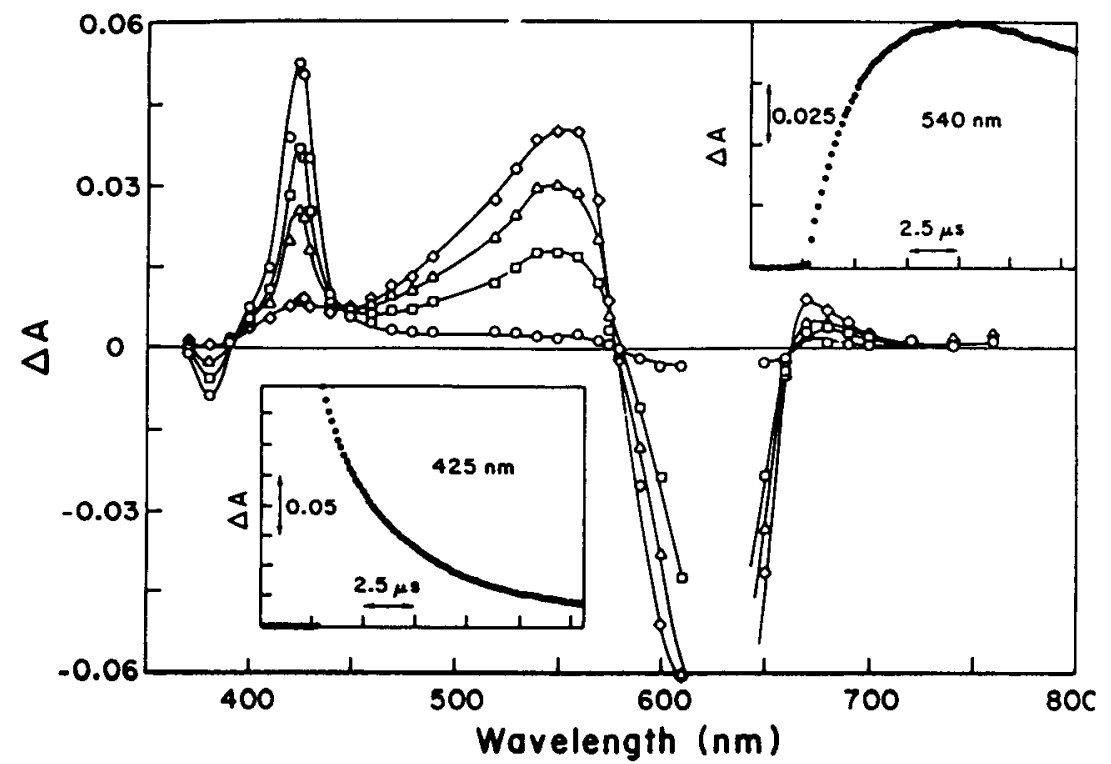

Figure 2. Energy transfer from triplet-excited 9,10-dibromoanthracene to SQ1 in methylene chloride. Transient absorption spectra were recorded, following $355 \mathrm{~nm}$ laser pulse excitation of a solution containing $0.1 \mathrm{mM} \mathrm{9,10-dibromoanthracene} \mathrm{and} 10 \mu \mathrm{M}$ SQ1 at time intervals $0(O), 1 \cdot 3(\square), 3 \cdot 0(\triangle)$ and $8 \cdot 0(\diamond) \mu \mathrm{s}$. The absorption time profiles in the insets show the decay of the 9,10-dibromoanthracene triplet at $425 \mathrm{~nm}$ and the formation of ${ }^{\mathrm{T}} \mathrm{SQ1}$ at $540 \mathrm{~nm}$. [Reprinted with permission from Kamat et al 1992 (C) 1992, Am. Chem. Soc.).] 
SQ2, respectively) and, hence, they can be oxidised by $\mathrm{RCl}$. The spectra of the dye radical cations obtained by pulse radiolysis are shown in figure 3. A strong overlap of SQ1 absorption with the ground state absorption of SQ1 was evident from the small bleaching of the $S_{0}-S_{1}$ band of SQ1.

Direct excitation of $\mathrm{SQ} 1$ at high laser doses also gave rise to transient spectra similar to those observed in the above pulse radiolysis experiments (figure 4) indicating the formation of dye radical cations under these conditions. The formation of the radical cation spectra at high laser doses, and the linear dependence of the transient absorbance on the square of the laser dose as shown in the inset of figure 5 , indicate

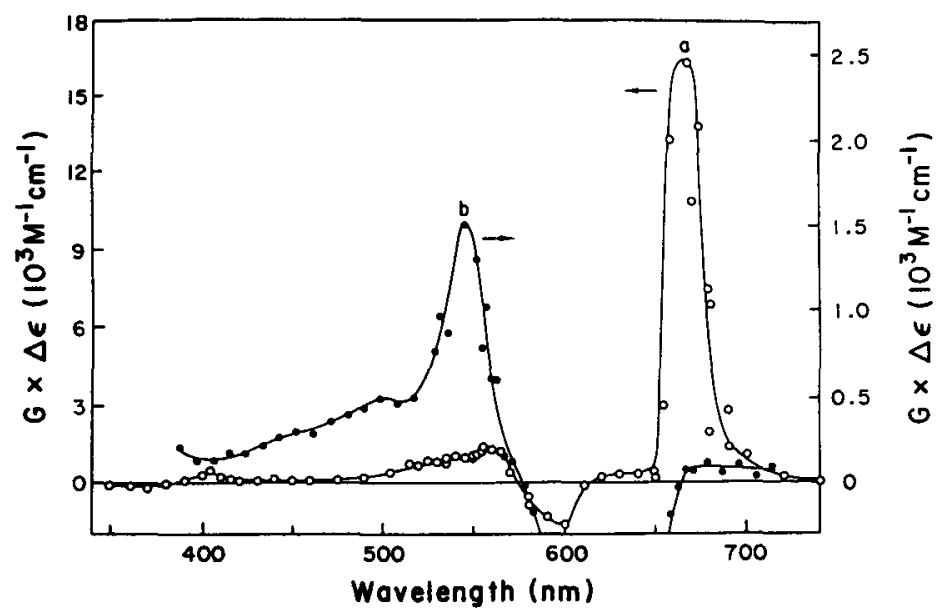

Figure 3. Transient absorption spectra of pulse radiolytically generated cation radical of (a) SQ1 and (b) SQ2 in methylene chloride. The difference absorption spectra were recorded, following the pulse radiolysis of $\mathrm{O}_{2}$ saturated $\mathrm{CH}_{2} \mathrm{Cl}_{2}$ solutions containing 10-20 $\mu \mathrm{M}$ of (a) SQ1 $(\Delta t=25 \mu \mathrm{s})$ and (b) SQ2 $(\Delta t=60 \mu \mathrm{s})$. [Reprinted with permission from Kamat et al 1992 ((C) 1992, Am. Chem. Soc.)]

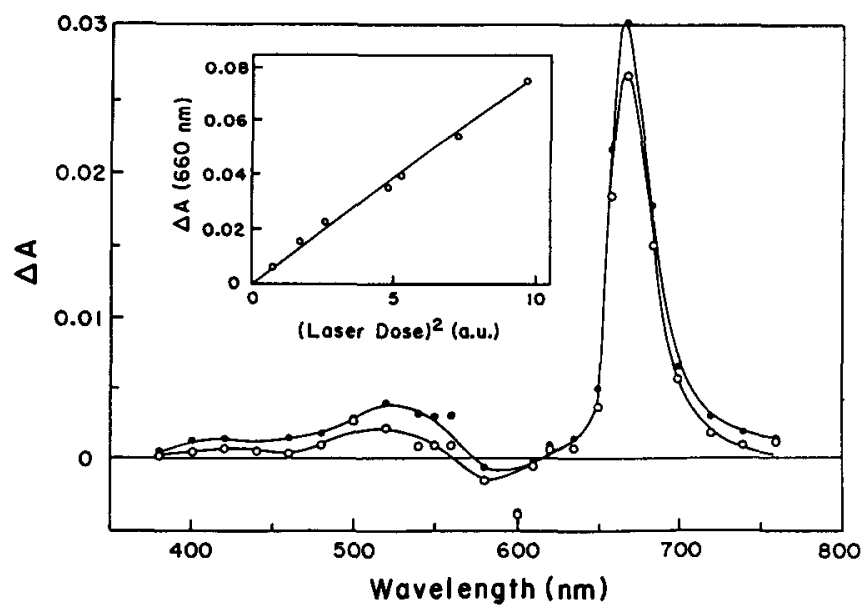

Figure 4. Photoionization of $\mathrm{SQ} 1$ in $\mathrm{CH}_{2} \mathrm{Cl}_{2}$. The different absorption spectra recorded (O) $0 \mu \mathrm{s}$ and (O) $50 \mu \mathrm{s}$ after $532 \mathrm{~nm}$ excitation of $10 \mu \mathrm{M}$ SQ1 in $\mathrm{CH}_{2} \mathrm{Cl}_{2}$. The inset shows the dependence of $\mathrm{SQ}^{+}{ }^{+}$yield $(\Delta A$ at $660 \mathrm{~nm})$ on the square of laser intensity. [Reprinted with permission from Kamat et al 1992 ( (C) 1992, Am. Chem. Soc.)] 


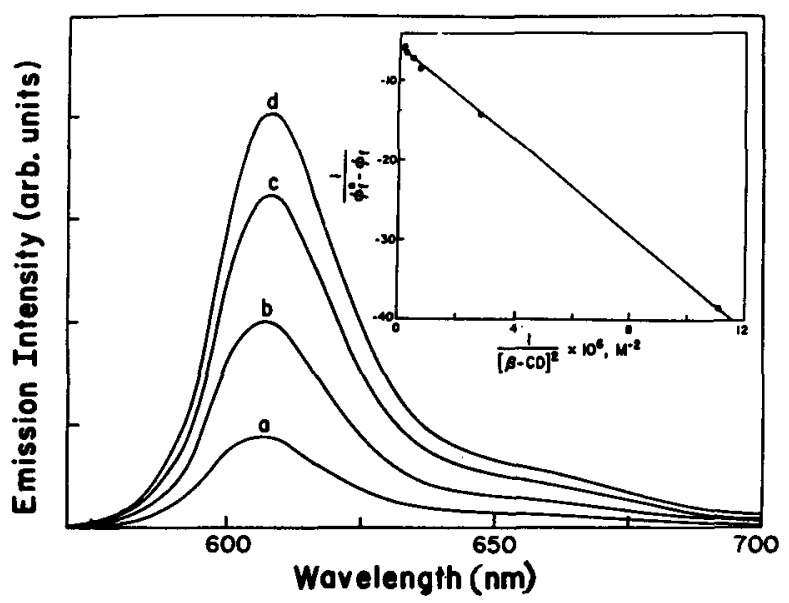

Figure 5. Influence of $\beta$-cyclodextrin concentration, $[\beta$-CD] on the emission spectrum of $3.5 \times 10^{-5} \mathrm{M} \mathrm{SQ} 5$ in aqueous solution at $p \mathrm{H}=8.6$; $[\beta-\mathrm{CD}]$ (a) 0.06 ; (b) 0.3 ; (c) 1.2 ; (d) $2.4 \mathrm{mM}$. Excitation wavelength, $560 \mathrm{~nm}$; inset shows plot of $1 /\left(\phi_{f}^{0}-\phi_{f}\right)$ vs $1 /[\beta-C D]^{2}$ for the fluorescence yield enhancement of $\mathrm{SQ5}^{-}$, on addition of $\beta$-CD. [Reprinted with permission from Das et al 1992b (C) 1992, R. Soc. Chem.)]

a biphotonic photoionization process as shown below

$$
\operatorname{SQ} 1\left(S_{0}\right) \stackrel{h v}{\rightarrow} \operatorname{SQ} 1\left(S_{1}\right) \stackrel{h v}{\rightarrow} \mathrm{SQ}^{++}+e^{-} \text {. }
$$

The spectrum of the radical anion of SQ1 was recorded by carrying out pulseradiolysis studies in nitrogen-saturated ethanolic solutions. A transient formed with absorption maximum around $405 \mathrm{~nm}$ was assigned to the SQ1 radical anion on the basis of the known reducing nature of irradiated ethanol solutions (Butler and Henglein 1980; Ford et al 1989). The formation of SQ1 ${ }^{-}$, has a half-life of $285 \mu$ s and this is attributed to the reaction of SQ1 with the solvated electron formed in the above system. No decay of the transient absorption was observed for up to $1 \mathrm{~ms}$.

3.1b Bis(3-acetyl-2,4-dimethylpyrrole)squaraine (SQ3): The spectral characteristics of the ground and excited states of SQ3, as well as the oxidised and reduced radical ions are shown in table 1 . Unlike SQ1 and SQ2, the pyrrole derivative (SQ3) was relatively non-fluorescent $\left(\phi_{f}=0.08\right)$ with an extremely short-lived singlet excited state $\left(\tau_{f}=222 \mathrm{ps}\right)$. The intersystem crossing efficiency was also very low $\left(\phi_{T}=0.02\right)$, although relatively higher than for SQ1 and SQ2. The spectra of the triplet state as well as the radical cation were generated and characterized as discussed earlier for SQ1 and SQ2 (Patrick et al 1992).

Photoelectrochemical reduction of SQ3 in colloidal semiconductor was carried with $308 \mathrm{~nm}$ laser pulse excitation. At this wavelength the absorbance of SQ3 is very low and the $\mathrm{TiO}_{2}$ colloid can be selectively excited. Since the reduction potential of SQ3 was estimated as $-0.43 \mathrm{~V}$, which is below the conduction band of the $\mathrm{TiO}_{2}$ semiconductor $\left(E_{\mathrm{CB}}=-0.5 \mathrm{~V}\right)$, reduction of the dye can be carried out as below (Kamat 1985):

$$
\begin{aligned}
\mathrm{TiO}_{2} & \stackrel{h v}{\rightarrow} \mathrm{TiO}_{2}\left(h^{+}+e^{-}\right), \\
\mathrm{TiO}_{2}(e)+\mathrm{SQ}_{3} & \rightarrow \mathrm{TiO}_{2}+\mathrm{SQ}^{\cdot-} .
\end{aligned}
$$


The absorption characteristics of the radical anion formed within the laser-flash duration is given in table 1 . Steady state irradiation at $325 \mathrm{~nm}$ of degassed colloidal solutions of $\mathrm{TiO}_{2}$ in acetonitrile containing SQ3 leads to a bleaching of the dye. On bubbling oxygen through this solution, the original colour is partially recovered. The bleaching of the dye may be attributed to the following disproportionation reactions of the radical anion.

$$
\begin{aligned}
& 2 \mathrm{SQ}^{--} \longrightarrow \mathrm{SQ}^{-}+\mathrm{SQ}^{2-}, \\
& \mathrm{SQ3}^{2-} \stackrel{2 \mathrm{H}^{+}}{\longrightarrow} \mathrm{SQ}^{2} \mathrm{H}_{2} .
\end{aligned}
$$

The structure of the reduced product $\mathrm{SQ} 3 \mathrm{H}_{2}$ is tentatively suggested as<smiles>CC(=O)c1c(C)[nH]c(C2=C(O)C(c3c(C)[nH]c(C)c3C)C2=O)c1C</smiles>

An analogous product has been observed in the case of a bis(methoxyphenyl)squaraine dye. This compound could be oxidised to the corresponding dye using strong oxidising agents such as bromine (Farnum et al 1968).

3.1c Bis(2,4-dihydroxyphenyl)squaraine (SQ4) and bis(2,4,6-trihydroxyphenyl)squaraine (SQ5): These dyes exist as several distinct ionic species in protonation equilibria with each other and the spectral properties of the different species are summarised in table 2 . The difference in spectral details can be attributed to protonation equilibria as described in scheme 1. In the case of SQ5, four distinct forms were observed (table 2). The emission spectra indicate that the singly deprotonated species ( $\mathrm{SQ}^{-} / \mathrm{SQ5}^{-}$) are the most fluorescent forms for both dyes. However, the much higher quantum yield of SQ4 as compared to SQ5, suggests that the additional hydroxy groups in the 6- and 6'- positions of SQ5 might distort the planarity of the molecules due to steric

Table 2. Absorption and emission characteristics of various ionic forms of bis $(2,4-$

\begin{tabular}{|c|c|c|c|c|c|c|c|}
\hline Dye & $\begin{array}{l}\text { Ionic form } \\
\qquad(p H)\end{array}$ & $\begin{array}{c}\text { Absorption } \\
\max \\
\text { (nm) }\end{array}$ & $\begin{array}{c}\text { Emission } \\
\max \\
(\mathrm{nm})\end{array}$ & $\phi_{f}$ & $\begin{array}{c}\tau_{s} \\
\text { (ps) }\end{array}$ & $\begin{array}{c}\text { Absorption } \\
\max \\
\left(S_{1}-S_{n}\right)(n m)\end{array}$ & $\begin{array}{c}\varepsilon_{\max }\left(S_{1}-S_{n}\right) \\
10^{4} \mathrm{M}^{-1} \mathrm{~cm}^{-1}\end{array}$ \\
\hline SQ4 & $\begin{array}{l}\mathrm{SQ4H}^{+}(1) \\
\text { SQ4(5) } \\
\text { SQ4}^{-}(9)\end{array}$ & $\begin{array}{l}563 \\
530 \\
588\end{array}$ & $\begin{array}{l}583 \\
582 \\
607\end{array}$ & $\begin{array}{l}0.010 \\
0.037 \\
0.092\end{array}$ & $\begin{array}{r}\leqslant 100 \\
130 \\
740\end{array}$ & $\begin{array}{c}c \\
449 \\
453\end{array}$ & $\begin{array}{c}c \\
3 \cdot 9^{d} \\
11 \cdot 0^{d}\end{array}$ \\
\hline SQ5 & $\begin{array}{l}\text { SQSH }^{+}(2) \\
\text { SQ5(5) } \\
\text { SQ5 }^{-}(8 \cdot 2) \\
\text { SQ5 }^{2-}(11)\end{array}$ & $\begin{array}{l}561 \\
508 \\
588 \\
543\end{array}$ & $\frac{-}{601}$ & $\begin{array}{c}<0.001 \\
<0.001 \\
0.01 \\
<0.001\end{array}$ & $\begin{array}{l}- \\
30^{e} \\
240^{e} \\
230^{c}\end{array}$ & $\begin{array}{l}457 \\
- \\
-\end{array}$ & $\begin{array}{l}2 \cdot 1^{d} \\
- \\
-\end{array}$ \\
\hline
\end{tabular}
dihydroxyphenyl)squaraine" (SQ4) and bis(2,4,6-trihydroxyphenyl)squaraine ${ }^{b}$ (SQ5).

In $10 \% v / v$ acetonitrile/water solution; ${ }^{b}$ in $30 \% v / v$ methanol/water solution; ${ }^{c}$ signal is too weak to analyse precisely; ${ }^{d}$ determined from ground state bleaching (it was assumed that the singlet state has no significant absorption at $S_{0}-S_{1}$ maximum); ' in $50 \% v / v$ acetonitrile water solution 
<smiles></smiles>

$S Q \angle H^{+}$

Scheme 1.<smiles>O=C1C=CC(=C2C(=O)C(c3ccc(O)cc3O)=C2O)C(O)=C1</smiles>

$+H^{+} \mid-H^{+}$<smiles>O=C1C=CC(=C2C(=O)C(c3ccc(O)cc3O)=C2[O-])C(O)=C1</smiles>

$S Q<-$

strain. The absorption characteristics of the excited singlet state formed by direct processes, as well as the triplet state formed through the DBA-sensitized processes, are summarised in table 2.

3.2 Fluorescence enhancement of bis(2,4,6-trihydroxyphenyl)squaraine (SQ5) by $\beta$-cyclodextrin and poly(4-vinylpyridine) microencapsulation

As discussed above, the anionic form of SQ5 has a fluorescence yield of 0.01 in methanol. The other ionic forms of SQ5 are relatively non-fluorescent. In aqueous medium, $\mathrm{SQ5}^{-}$is relatively non-fluorescent $\left(\phi_{f}=0.001\right)$ and also very sensitive to air oxidation. Addition of $\beta$-cyclodextrin $(\beta-\mathrm{CD})$ to an aqueous solution of SQ5

Table 3. Absorption and emission characteristics of bis(2,4,6-trihydroxyphenyl) squaraine (SQ5) in the presence and absence of (a) $\beta$-cyclodextrin $[\beta-C D]$ in water $(p \mathrm{H}=8 \cdot 6)$ and poly(4-vinylpyridine) $[\mathrm{P} 4 \mathrm{VP}]$ in methanol.

\begin{tabular}{|c|c|c|c|c|c|c|}
\hline \multirow[b]{2}{*}{ Solvent } & & \multicolumn{2}{|c|}{$\lambda \max (\mathrm{nm})$} & \multirow[b]{2}{*}{$\phi_{f}$} & \multirow{2}{*}{$\begin{array}{c}\tau_{s} \\
(\mathrm{ps})\end{array}$} & \multirow{2}{*}{$\begin{array}{c}\text { Absorption } \\
\max \\
\left(S_{1}-S_{n}\right)(\mathrm{nm})\end{array}$} \\
\hline & & Absorption & Emission & & & \\
\hline \multicolumn{7}{|c|}{$[\beta-C D] m M$} \\
\hline Water & 0 & 584 & 595 & 0.002 & 85 & \\
\hline Water & $2 \cdot 4$ & 598 & 608 & 0.16 & 1200 & \\
\hline $\begin{array}{c}\text { Methanol/water } \\
(30 \% v / v)\end{array}$ & 0 & 588 & 598 & 0.01 & - & \\
\hline $\begin{array}{c}\text { Methanol/water } \\
(30 \% v / v)\end{array}$ & $1 \cdot 5$ & 591 & 601 & $0-01$ & - & \\
\hline \multicolumn{7}{|c|}{$[P 4 V P] M$} \\
\hline Methanol & 0 & 510 & 597 & $<0.001$ & $\$ 30$ & 414 \\
\hline Methanol & $0 \cdot 1$ & 510,602 & 610 & 0.02 & $\sim 100$ & $\mathbf{a}$ \\
\hline $\begin{array}{l}\text { Methanol } \\
\text { containing } \\
3 \mathrm{mM} \mathrm{KOH}\end{array}$ & 0 & 588 & 601 & 0.02 & 185 & 420,490 \\
\hline $\begin{array}{l}\text { Methanol } \\
\text { containing } \\
3 \mathrm{mM} \mathrm{KOH}\end{array}$ & $0 \cdot 1$ & 602 & 615 & 0.2 & 2000 & 425,495 \\
\hline
\end{tabular}

a Signal is too weak to be analysed precisely 
brings about a significant enhancement (nearly 90-fold) in the fluorescence yield of the anion (figure 5), which is accompanied by a shift of about $13-14 \mathrm{~nm}$ in the absorption and emission bands (table 3 ). Complexation of the dye by $\beta$-CD also significantly enhances the chemical stability. The Benesi-Hildebrand analysis of the emission data as a function of $\beta$-CD concentration (inset, figure 5) suggests a 2:1 host-guest complex formation, i.e. two $\beta$-CD molecules complex with one anion molecule. $\beta$-CD encapsulation can bring about a decrease in the rotational freedom of the phenyl groups, leading to an increase in the fluorescence yield. For the uncomplexed dye anion, hydrogen bonding with solvent molecules is an additional factor influencing the non-radiative decay route. Encapsulation of the dye anion by two $\beta$-CD molecules is likely to exclude the intermolecular hydrogen bonding between the anion and water molecules. In the absence of such intermolecular hydrogen bonding, the central oxygen atoms of the cyclobutane ring would preferentially form hydrogen bonds with the $\mathrm{OH}$ groups in the adjacent phenyl groups, bringing about a rigidization of the molecule. Such intramolecular hydrogen bonding was shown to enhance fluorescence yield for the dimethylanilino derivatives (Kamat et al 1992). The fluorescence lifetime $\left(\tau_{f}=1.23 \mathrm{~ns}\right)$ of the complexed dye anion is much higher than that of the uncomplexed anion ( $85 \mathrm{ps}$ ). Intersystem crossing efficiency is a minor pathway for decay of the excited singlet states of both the uncomplexed and complexed dye anions, as evidenced by the low triplet yields.

In basic methanolic solutions of SQ5, addition of P4VP brings about a clear red shift in the absorption band of the dye anion. The red shift in the absorption band is accompanied by a significant enhancement of the fluorescence quantum yield (figure 6; table 3). In neutral methanolic solution, the dye is predominantly in the neutral form, with minor amounts of the anion being present. Addition of P4VP to neutral methanolic solutions brings about a selective complexation of the ionic form, accompanied by a slight enhancement in fluorescence yields (Das et al 1992).

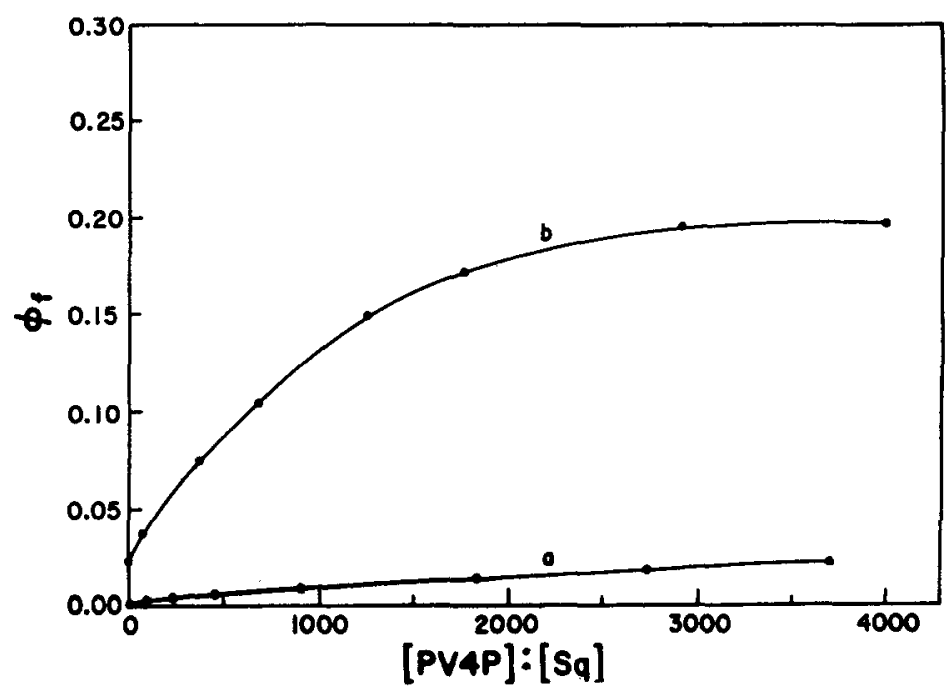

Figure 6. Dependence of fluorescence quantum yield of SQ5 on the concentration of P4VP: (a) neutral methanol, (b) basic methanol $\left([\mathrm{KOH}]=3.0 \times 10^{-3} \mathrm{M}\right)$. The excitation wavelength was $540 \mathrm{~nm}$ and the absorption at this wavelength was adjusted to 0.1 . [Reprinted with permission from Das et al 1992a (C) 1992, Am. Chem. Soc.)] 
Hydrophobic interactions between the dye anion and P4VP may be attributed to the selective complexation of the anion. At the low concentrations of P4VP employed, the macroviscosity will not affect the fluorescence yields very significantly. Interestingly, addition of poly (2-vinylpyridine) does not bring about any fluorescence enhancement, thus ruling out macroviscosity effects due to the addition of polymer. Hydrogen bonding between the nitrogen atom of P4VP and the anion seems to be the major factor in bringing about complex formation. In P2VP, the nitrogen atom may be too sterically hindered for this purpose.

\subsection{Interaction of squaraines with $\mathrm{TiO}_{2}$}

The bis [(4-dimethylamino-2-hydroxy) phenyl] squaraine (SQ2) dye strongly interacts with colloidal $\mathrm{TiO}_{2}$, as indicated by the changes in the absorption spectrum (figure 7). The presence of an isobestic point at $650 \mathrm{~nm}$ in these absorptions shows the existence of the dye in the equilibrium between absorbed and unabsorbed states. The apparent association constant, as determined by the Benesi-Hildebrand method, was $2667 \mathrm{M}^{-1}$, indicating strong interaction between the dye and $\mathrm{TiO}_{2}$ (Kamat et al 1991).

$$
\mathrm{TiO}_{2}+\mathrm{SQ} 2 \stackrel{\mathrm{K}_{\mathrm{app}}}{\rightleftharpoons}\left[\mathrm{SQ} 2--\mathrm{TiO}_{2}\right]
$$

The fluorescence of the dye is strongly quenched by $\mathrm{TiO}_{2}$. This could be the result of charge injection from the excited state to the conduction band of $\mathrm{TiO}_{2}$. The oxidation potential of SQ1 is 1.5 V vs NHE (Law 1990), which is favourable for such charge injection. Picosecond laser flash photolysis of solutions of the dye with and without $\mathrm{TiO}_{2}$ give the transient spectra shown in figure 8. In the absence of $\mathrm{TiO}_{2}$, the spectrum characteristic of the excited singlet state of SQ1 is obtained. However, in the presence of colloidal $\mathrm{TiO}_{2}$, an additional absorption peak appears at $580 \mathrm{~nm}$. The absorption band at $580 \mathrm{~nm}$ closely matches the absorption characteristics of the

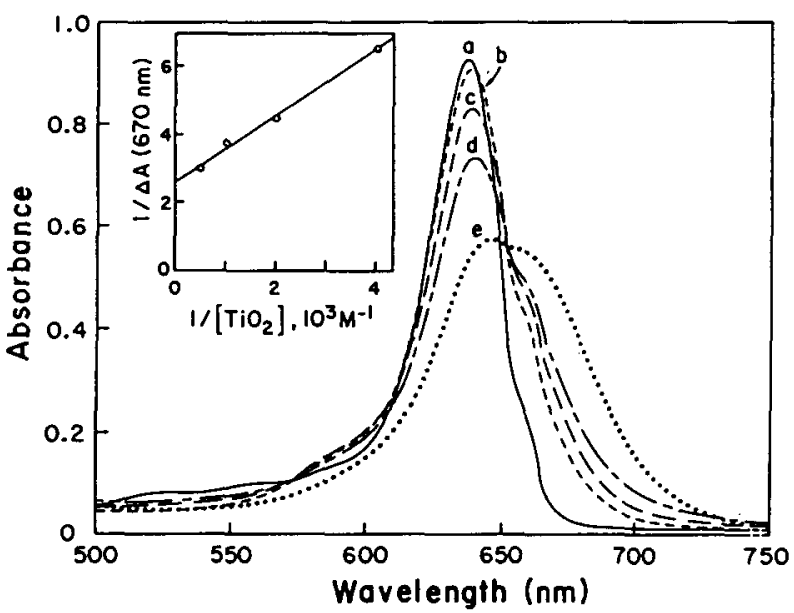

Figure 7. Absorption spectra of SQ1 (3 mM) in $40 \% \mathrm{v} / \mathrm{v}$ methylene chloride and $60 \% \mathrm{v} / \mathrm{v}$ acetonitrile containing (a) 0 , (b) 0.25 , (c) 0.5 , (d) 1 and (e) $2 \mu \mathrm{M}$ of colloidal $\mathrm{TiO}_{2}$. The insert shows the fitting of the $670 \mathrm{~nm}$ absorption to the Benesi-Hildebrand plot. [Reprinted with permission from Kamat et al 1991 (C) 1991, Elsevier Science Publishers, BV.)] 


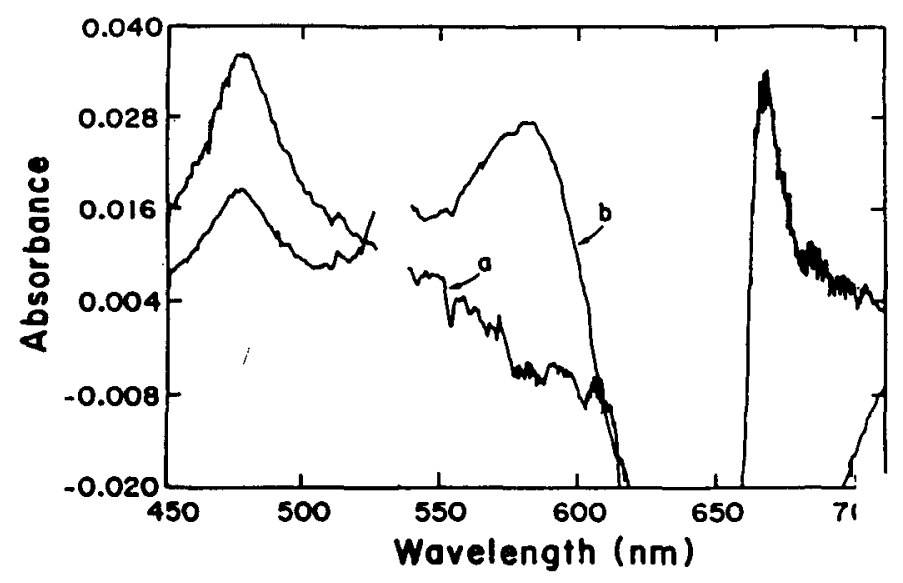

Figure 8. Transient absorption spectra recorded immediately after $532 \mathrm{~nm}$ laser pulse excitation $(\Delta t=0 \mathrm{ps})$ of SQ1 in $50 \% v / v$ dichloromethane and $50 \% v / v$ acetonitrile, without (a) and with (b) colloidal $\mathrm{TiO}_{2}(2 \cdot 5 \mu \mathrm{M}$ ). (The absorption around $532 \mathrm{~nm}$ is masked because of the interference from the excitation pulse scatter.) [Reprinted with permission from Kamat et al 1991 (C) 1991, Elsevier Science Publishers, BV.)]

dye radical cation, observed in the pulse radiolysis studies (table 1). The difference in the medium and adsorption on $\mathrm{TiO}_{2}$ surface may be responsible for the small red shift observed $(20 \mathrm{~nm})$. The charge injection may be represented as

$$
\mathrm{SQ}_{2} *(\mathrm{~S} 1)+\mathrm{TiO}_{2} \rightarrow \mathrm{SQ}^{+}+\mathrm{TiO}_{2}(e) .
$$

The decay of the transient was analysed to give a lifetime of $270 \mathrm{ps}$ for the dye radical cation $\left(k=2.7 \times 10^{-10} \mathrm{~s}^{-1}\right)$.

The photosensitization of $\mathrm{TiO}_{2}$ particulate films by the squaraine dye, SQ4, has also been investigated (Kamat et al 1993). The sensitizing behaviour was probed by adsorbing the dye on $\mathrm{TiO}_{2}$ colloid-coated $\mathrm{OTE}\left(\mathrm{OTE} / \mathrm{TiO}_{2}\right)$ electrode. The photoresponse of the dye-modified OTE/ $\mathrm{TiO}_{2}$ electrode is shown in figure 9. Upon illumination of this electrode with visible light $(500 \mathrm{~nm})$, a rise in photovoltage is seen. The open circuit voltage remained steady as long as the irradiation was continued. When the lamp was turned off the voltage quickly dropped to the dark value. The photoelectrochemical effect at the $\mathrm{OTE} / \mathrm{TiO}_{2} /$ dye was reproducible over several cycles of irradiation. The photocurrent action spectrum closely matches that of the dye anion. The maximum photon-to-photocurrent efficiency obtained was only $0.05 \%$, which is considerably lower than the fluorescence quantum efficiency of 3-9\%. This shows that the reverse electron transfer is still a major factor in limiting the photosensitization. By suitable modification of the dye or by using a suitable redox coupled semiconductor system it should be possible to improve the performance of such photoelectrochemical cells.

\section{Conclusions}

The strong absorption and emission bands of the squaraine dyes in the visible and near infrared regions, along with their ability to undergo reversible oxidative and 

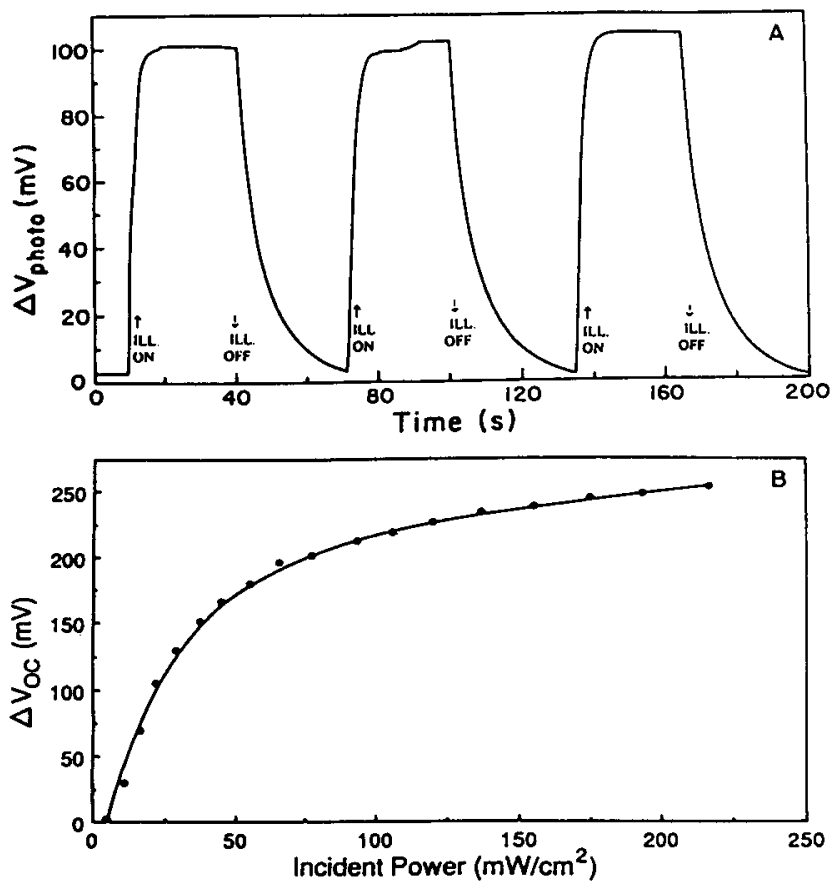

Figure 9. (A) The photovoltage (open-circuit) response of a squaraine dye (SQ4) modified electrode (OTE $/ \mathrm{TiO}_{2} / \mathrm{SQ}^{-}$) to illumination at $500 \mathrm{~nm}$ in a photoelectrochemical cell containing $\mathrm{Pt}$ foil as counter electrode and aqueous $1.5 \mathrm{M} \mathrm{KCl}$ as electrolyte. (B) The dependence of maximum open-circuit photovoltage of OTE/TiO $/ \mathrm{SQ}^{-}$on the incident light intensity. [Reprinted with permission from Kamat et al 1991 ( (C) 1991, R. Soc. Chem.)]

reductive photoelectron transfer processes, make these dyes highly suitable for photosensitization purposes. These dyes are capable of sensitizing semiconductors such as $\mathrm{TiO}_{2}$. The extreme sensitivity of the absorption and emission properties to the solvent media can be utilised for probing hydrophobic and hydrophilic environments.

\section{Acknowledgements}

We (SD, KGT and MVG) thank the Council of Scientific and Industrial Research, Government of India, Regional Research Laboratory, Trivandrum, (MVG) Jawaharlal Nehru Centre for Advanced Scientific Research and (PVK and MVG) the Office of Basic Energy Sciences of the US Department of Energy for financial support of this work. This is Contribution No. RRLT-PRU-30 from RRL, Trivandrum and NDRL3601 from the Notre Dame Radiation Laboratory.

\section{References}

Bigelow R W and Freund H J 1986 J. Chem. Phys. 107159

Butler J and Henglein A 1980 Radiat. Phys. Chem. 15603 
Carmichael I and Hug G L 1986 J. Phys. Chem., Ref. Data 1526

Das S, Kamat P V, De la Barre B, Thomas K G, Ajayaghosh A and George M V 1992a J. Phys. Chem. 9610327

Das S, Thomas K G, George M V and Kamat P V 1992b J. Chem. Soc., Faraday Trans. 883419

Emmelius M, Pawloski G and Vollmann H W 1989 Angew. Chem., Int. Ed. Engl. 281445

Emsley J 1992 New Sci. 13516

Fabian J, Nakazumi H and Matsuoka M 1992 Chem. Rev. 921197

Farnum D G, Webster B and Wolf A D 1968 Tetrahedron Lett. 5003

Ford W E, Hiratsuka H and Kamat P V 1989 J. Phys. Chem. 936692

Kamat P V 1985a J. Photochem. 28513

Kamat P V 1985b J. Chem. Soc., Faraday Trans. 181509

Kamat P V 1989 J. Phys. Chem. 932873

Kamat P V, Das S, Thomas K G and George M V 1991 Chem. Phys. Lett. 88671

Kamat P V, Das S, Thomas K G and George M V 1992 J. Phys. Chem. 96195

Kamat P V, Hotchandani S, De Lind M, Thomas K G, Das S and George M V 1993 J. Chem. Soc., Faraday Trans. 892397

Law K Y 1987 J. Phys. Chem. 915184

Law K Y 1989 J. Phys. Chem. 935925

Law K Y 1990 J. Imaging Sci. 3431

Law K Y 1993 Chem. Rev. 449

Law K Y and Bailey F C 1987 J. Imaging Sci. 31192

Loutfy R O, Hsiao C K and Kazmaier P M 1983 Photogr. Sci. Eng. 275

Morel D L, Stogryn E L, Ghosh A K, Feng T, Purwin P E, Shaw R F, Fishman C, Bird G R and Piechowski A P 1984 J. Phys. Chem. 88923

Patrick B, George M V, Kamat P V, Das S and Thomas K G 1992 J. Chem. Soc., Faraday Trans. 88671

Piechowski A, Bird G R, Morel D L and Stogryn E L 1984 J. Phys. Chem. 88933

Schmidt A H 1980 Synthesis 961

Seitz G and Imming P 1992 Chem. Rev. 921227

Sprenger H E and Ziegenbein 1966 Angew. Chem., Int. Ed. Engl. 5894

Sprenger H E and Ziegenbein 1968 Angew. Chem., Int. Ed. Engl. 7530

Tam A C 1980 Appl. Phys. Lett. 37978

Vieira F L V, Costa S M B and Pereira E 1991 J. Photochem. Photobiol. A55 361 